\title{
On only-pragmatically driven intonation change
}

\author{
Marco Barone
}

Department of languages and literature, Federal University of Pernambuco, Brazil https://doi.org/10.36505/ExLing-2020/11/0011/000426

\begin{abstract}
The intonation system of the Italian variety of Pescara was documented and two sentence types (neutral polar questions and contrastive focus statements) were found to exhibit the same two pitch accents as allophonic variants by the old speakers. However, moving on the new generation, the variations of the two sentence types shows different evolutions: both variants are used, remaining distinct, for contrastive focus, whereas they mainly fuse into a "midway" pattern, when used for questions. The asymmetry can only be ascribed to the pragmatics and not to the phonetic forms of the patterns, as these were originally equal across the two sentence types. This suggests that polar questions are more kin to phonetic convergence than contrastive statements.
\end{abstract}

Keywords: intonation phonology, intonation change, discourse completion task, postlexical meanings, phonetic convergence

\section{Introduction}

Intonation phonology studies the conventional associations, in a given intonation language or variety, between surface phonetic forms (contours and their smaller units) and post-lexical meanings, also referred to as "sentence types" (specifying modality and pragmatic function, including its nuances). Roughly speaking, it can be though of as a type of "phono-pragmatics" (as opposed to the classical "phonosemantics"): a correspondence, not always oneto-one, between a phonetic level (signifier) and a pragmatic level (signified).

In the intonational sign, just like in standard phonology, the signifier is subject to variation across languages, whereas meanings are mainly conceived as a fixed, universal layer (although cross-cultural differences in their categorization and their reanalysis in time cannot be excluded). This is why studies on intonation variation and change usually work one sentence type at a time and compare the contours used for it. Since these studies focus on one or a few sentence types only, they usually build their corpus by eliciting only those, and analyzing the variation of contours (or smaller patterns) associated to them. However, when an asymmetry between two signs is found, it is hard to assess whether it is due to an asymmetry of the signifiers, or of the meanings, unless either the signifiers or the meanings coincide across the two signs.

Intonation change studies mainly amount to contact-induced change. Among them, some explore variation across age groups (Heffernan 2006, Alvord 2010). As change is not uniform across speakers, it can also be detected by the variation it leaves behind, especially in contact situations, where control groups

ExLing 2020: Proceedings of $11^{\text {th }}$ International Conference of Experimental Linguistics, 12-14 October 2020, Athens, Greece 
help detect which are, for a given group, the native (conservative) variants and those of exposure (innovative) and thus the direction of change.

Recent studies have seen change as the long-term outcome of the actual interaction of speakers of mutually intelligible systems (varieties of the same language), rather than occurring in the mind of bilingual speakers, supporting this way hypotheses such as indirect transfer and language accommodation theory: convergence of speakers in daily interaction leads to the surface forms of the systems becoming more similar to one another, unconsciously and gradually (phonetic convergence). This may lead to interlanguages with phonetically intermediate patterns, which in segmental phonology Chambers \& Trudgill (1980) refer to as "fudged lects", as opposed to "mixing lects", which contain patterns from both donor languages but no further ones.

Studies on intonation contact, transfer and accommodation have found the intonation contours of yes-no questions more prone to change towards nonnative contours than those of statements. O'Rourke (2005) observes that Cuzco speakers maintained their conservative L1-Quechua contour in their L2 Spanish for declaratives, but they acquired the L2-Spanish pattern for polar questions. Romera \& Elordieta (2013) find that the contours used by a Catalandominant and a Spanish-dominant groups of Majorcan speakers for statements and those used for questions evolved differently: the two groups' original patterns would phonetically converge to an intermediate form only in the case of questions. Dealing with different allophonic distributions, the authors did not ascribe the asymmetric behavior to the pragmatics of questions vs statements and rather posit a role of the difference in salience of the contours' shape, that is, a (language specific) characteristic of the surface form. Another study (Troncoso-Ruiz \& Elordieta 2017) finds that Andalusian speakers reallocated in Asturias accommodate their behavior to the local intonation more frequently for questions than for statements. Again, as the contours of the two varieties are more distinct for questions than for statements, the authors ascribe the asymmetry to salience of the signifier.

\section{Methods}

Our corpus is part of a survey on Pescara Italian intonation, made within the Interactive Atlas of Romance Intonation (Prieto, Borràs-Comes \& Roseano (Coords.) 2010-2014), using the Discourse Completion Task (Blum-Kulka et al. 1989, Vanrell et al. 2018), a role-play interview aimed at eliciting different speech acts, by presenting imaginary contexts participants are supposed to react to by uttering, for each one, a specific target sentence type. The task was adapted to Italian by Barbara Gili Fivela (Gili Fivela et al. 2015) and contains 57 situations, targeting 35 sentence types. The documentation of Pescara Italian intonation included 6 old speakers (63-68 y.o.) and 8 young speakers (22-37 y.o.), for it was aimed at capturing information on the influence of the substratum language the elder speakers are more proficient in. 


\section{Data analysis and results}

Both for contrastive statements and information-seeking yes-no questions, old speakers of Pescara Italian show the same allophonic variation of pitch accents, with 2 main pitch accents (Figure 1): A) a "pre-tonic peak" fall, transferred from the local language, Pescarese, with a high peak aligned at the end of the pre-tonic syllable, and B) a "tonic peak" late fall with a peak fully inside the tonic vowel, influenced from Rome Italian, together with a minority of intermediate patterns, being either overlapping patterns ("double" peak (C1) or plateau (C2)) or a midway pattern, a single "midway peak" (D) usually aligned between the onset and the nucleus of the tonic syllable.

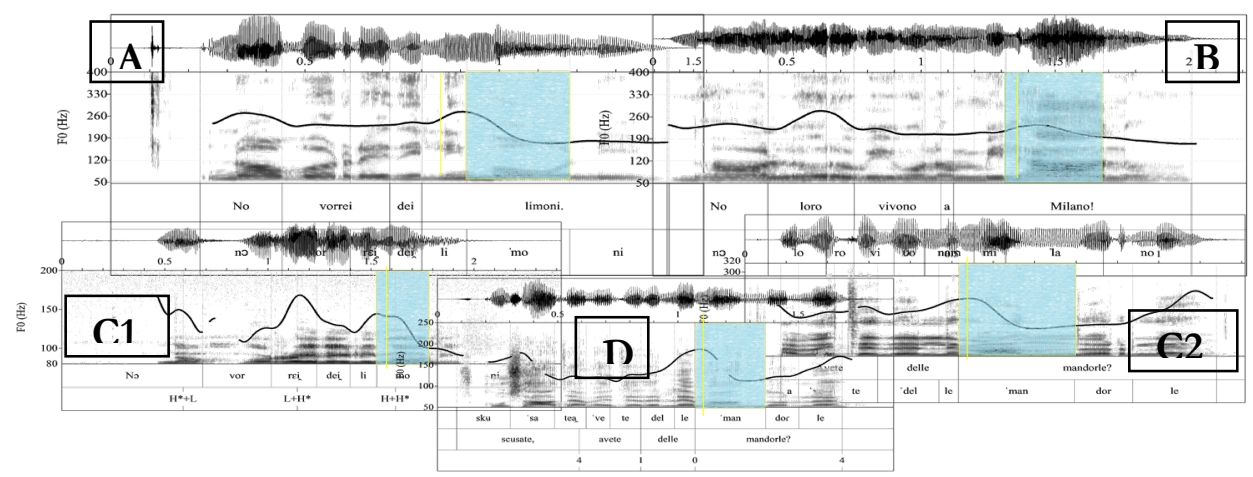

Figure 1. Pretonic peak (A, left), tonic peak (B, right), overlapping (C1, C2) and midway peak (D, bottom middle): highlighted squares bound the tonic syllable.

Table 1. Scatter plot: alignment of $1^{\text {st }}$ peak ( $\mathrm{x}$ axis) and $2^{\text {nd }}$ peak (y axis), which are taken to coincide if there is only one peak (on the diagonal: types A, B, D).

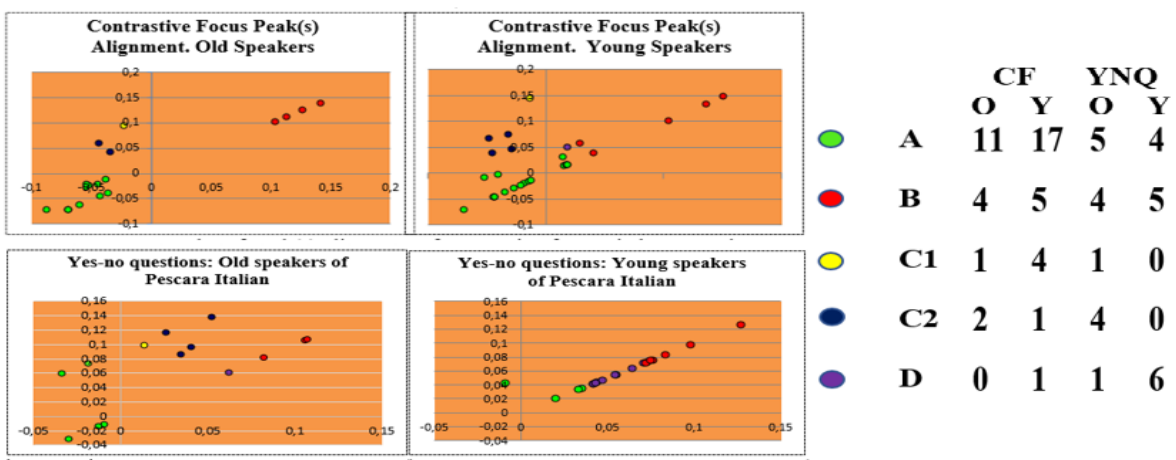

When coming to the youngsters, the evolution of this common distribution is sensitive to pragmatics: when associated to contrastive focus, patterns A) and 
B) prevail, and intermediate patterns mildly increase, whereas in informationseeking questions type D) outnumbers A) and B) (6 occurrences, see Table 1)

\section{Conclusion}

As we deal with the same accents for the two sentence types, the asymmetry in change observed between the two sentence types can only depend on their pragmatics. As a possible reason, we posit that in questions speakers, needing information, are in a subordinate role and converge more (Gasoriek et al. 2015), leading to question contours phonetically converge into midway fudged forms, more than contrastive statements, which are a more assertive type. We suggest that researchers, whenever possible, carry on the documentation of all sentence types of a system, even if they want to analyze only one, in order to get more chances of coming across similar findings.

\section{References}

Alvord, S. 2010. Variation in Miami Cuban Spanish Interrogative Intonation. Hispánia 93 (2): 235-255.

Blum-Kulka, S., House, J., Kasper, G. 1989. Investigating cross-cultural pragmatics: an introductory overview. In S. Blum-Kulka, J. House, G. Kasper (Eds.), CrossCultural Pragmatics: Requests and Apologies. Norwood, NJ: Ablex, 1-34.

Chambers, J. K., Trudgill, P. 1980. Dialectology. Cambridge: CUP.

Gasoriek, J., Giles, H., Soliz, J. 2015. Accommodating new vistas. Langauge \& Communication 41: 1-5.

Gili Fivela, B. et al. 2015. Intonational phonology of the regional varieties of Italian. In: S. Frota, P. Prieto (Eds.) Intonation in Romance. Oxford: OUP, 140-197.

Heffernan, K. 2006. Prosodic levelling during language shift: Okinawan approximations of Japanese pitch accent. Journal of Sociolinguistics, 10: 641-666.

O'Rourke, E. 2005. Intonation and language contact: a case study of two varieties of Peruvian Spanish. Ph.D thesis, University of Illinois at Urbana-Champaign.

Prieto, P., Borràs-Comes, J., Roseano, P. (Coords.) (2010-2014). Interactive Atlas of Romance Intonation. Web page: <http://prosodia.upf.edu/iari/>.

Romera, M., Elordieta, G. 2013. Prosodic accommodation in language contact: Spanish intonation in Majorca. International Journal of the Sociology of Language 221: $127-$ 151.

Troncoso-Ruiz A., Elordieta, G. 2017. Prosodic accommodation and salience: The nuclear contours of Andalusian Spanish speakers in Asturias. Loquens 4 (2).

Vanrell, M., Feldausen, I, Astruc, Ll. The Discourse Completion Task in Romance prosody research: status quo and outlook. In: I. Feldhausen, J. Fließbach \& M. Vanrell (Eds.) Methods in prosody: A Romance language perspective. Berlin: Language Science Press, 191-227. 